\title{
Structural Mapping of the 1999 Chi-Chi Earthquake Fault, Taiwan by Seismic Reflection Methods
}

\author{
Chien-Ying Wang ${ }^{1}{ }^{*}$, Chien-Li Li ${ }^{1}$, Fu-Chen $\mathrm{Su}^{2}$, Ming-Tar Leu ${ }^{2}$, Ming-Shan $\mathrm{Wu}^{2}$, \\ Shao-Huei Lai ${ }^{2}$, and Chir-Cherng Chern ${ }^{2}$
}

(Manuscript received 1 March 2002, in final form 8 July 2002)

\begin{abstract}
Several seismic reflection surveys were conducted to investigate the seismogenic structure of the 1999 Chi-Chi earthquake $(M w=7.6)$ in central Taiwan. Two $40 \mathrm{~km}$-long seismic profiles that crossed the area near the epicenter were acquired using the deep reflection method with a targeting depth of $10 \mathrm{~km}$, to search for the decollement boundary. One of the obtained sections shows a clear reflection event that dips to the east by $40^{\circ}$ until reaching a depth of $8 \mathrm{~km}$ where the earthquake's source was located. This slant event is unambiguously related to the thrusting Chelungpu fault surface. The abundant eastward dipping reflectors on the deep reflection sections faithfully describe thrusting features predicted by the earthquake faulting model. Besides these deep reflections, we also used many shallow seismic reflection lines to delineate the structures in the northern portion of the fault zone, where large ruptures (about $10 \mathrm{~m}$ ) occurred both on the surface and underground. The 3D structure of the fault surface can be deduced using this cost-effective approach. Although the depth imaged may be limited (e.g., $3 \mathrm{~km}$ ), shallow seismic data still provides reliable information for the study of large ruptures, and to make better plans for deep wells that might be drilled in this area in the future.
\end{abstract}

(Key words: Chelungpu fault, Deep reflections, Shallow reflections)

\section{INTRODUCTION}

The most significant feature in the Bouguer gravity anomaly map of Taiwan is an overall gravity low (-61 mgal) near the center of the island (Fig. 1a, inlet). It covers an $80 \mathrm{~km} \mathrm{x} 80 \mathrm{~km}$ area, contoured by -50 mgal curves, which includes the Taichung basin, the Puli basin, and the foothills between them (Fig. 1a). This area happens to be the region where the 1999 Chi-Chi

\footnotetext{
${ }^{1}$ Institute of Geophysics, National Central University, Chung-Li, Taiwan

${ }^{2}$ Chinese Petroleum Corporation, Taiwan

${ }^{*}$ Corresponding author address: Prof. Chien-Ying Wang, Institute of Geophysics, National Central University, Chung-Li, Taiwan, ROC; E-mail: wangcy@cc.ncu.edu.tw
} 
(a)

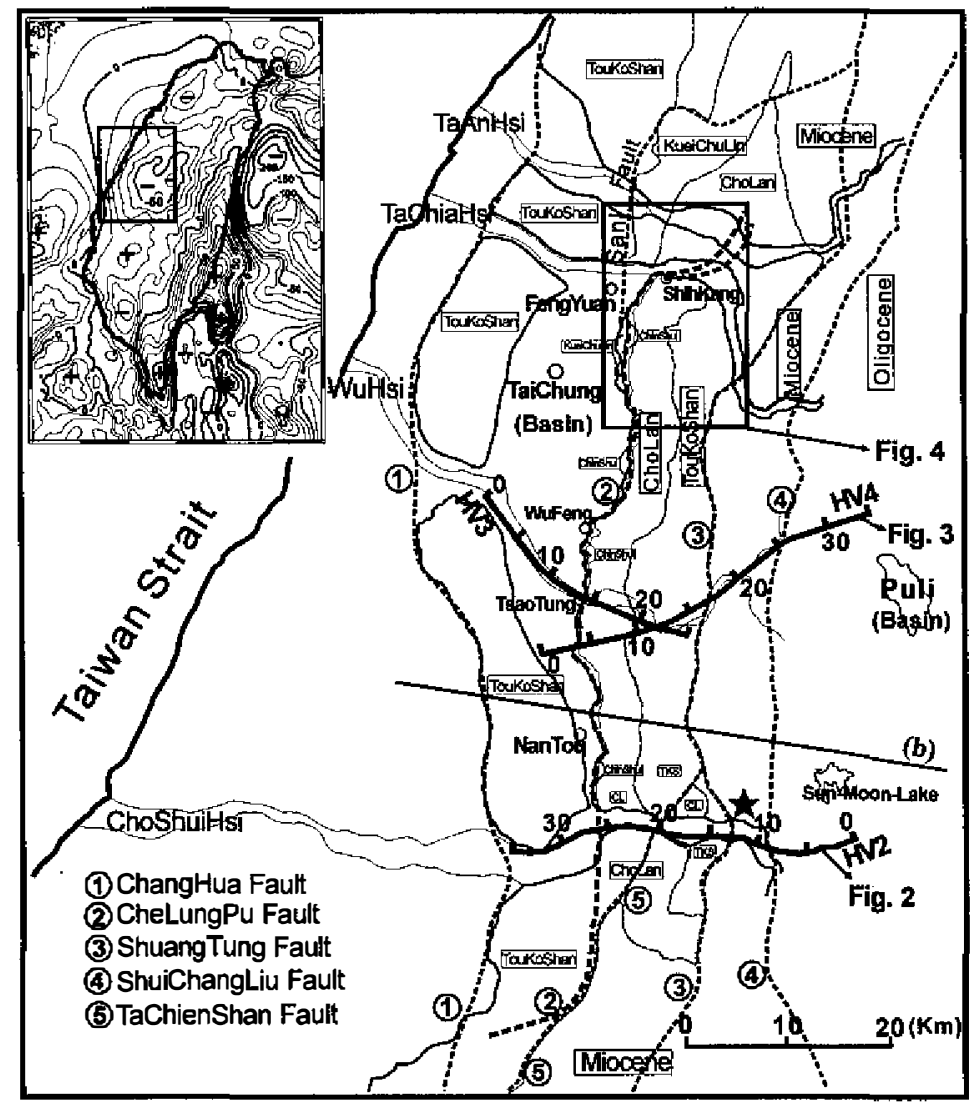

(b)

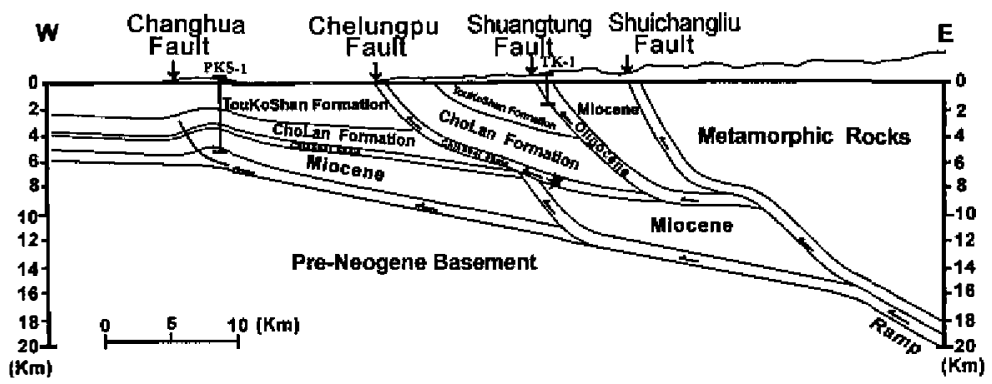

Fig. 1. (a) A simplified geologic map of the area surrounding the Chelungpu fault modified from CPC (1982), and (b) a sketched cross-section based on the thin-skinned thrust model (Wang et al. 2000). The inlet in (a) describes the Bouguer gravity map of the Taiwan island. A gravity low is apparent at the middle of the island. The imbricated structures under western Taiwan have been formed due to thrusting along four sequential faults (dashed lines). Two deep seismic reflection lines of Figs. 2 and 3 and the area to be studied in Fig. 4 are indicated in (a). The star denotes the Chi-Chi earthquake epicenter. 
earthquake $(\mathrm{Mw}=7.6)$ and its aftershocks were distributed (Kao and Chen 2000 ; Shin and Teng 2001). Two apparently conflicting theories have been proposed to explain this gravity low. One is the lithosphere collision model of Wu et al. (1997), which attributes this gravity low to the presence of a thick crust $(50 \mathrm{~km}$ ?) under the Central Mountain Range and the western foothills due to the collision by the Coastal Mountain Range from the east. Another theory is the thin-skinned thrust model of Suppe (1985), which allows structures above a decollement ( $8-10 \mathrm{~km}$ deep) to be thrust into imbricated forms. Low density material is thought to be moved to deep places, which produces the gravity low (Yen et al. 1998). A detailed mapping of the structure beneath this anomalous gravity low area is necessary to ascertain which of these two models is more accurate.

The 1999 Chi-Chi earthquake provided some evidences in favor of the thin-skinned thrust model (Wang et al. 2000). This model implies that the $8 \mathrm{~km}$ deep earthquake triggered the existing Chelungpu fault, causing it to slide along a weak, shallowly dipping $\left(30^{\circ}\right)$ shale layer (Chinshui shale) until breaking the surface (Fig. 1b). The most astonishing behavior of the Chelungpu fault is that its largest displacements, both on the surface (up to $9.8 \mathrm{~m}$ horizontally, $5.6 \mathrm{~m}$ vertically) and underground (up to $12 \mathrm{~m}$ ), were not in the source area, but concentrated in an area $50 \mathrm{~km}$ north of the epicenter (Ma et al. 2001 ; Chen et al. 2001). The course of this $90 \mathrm{~km}$ fault trace also turns from a south-north to a northeast direction in this region (the Fengyuan-Shihkang area, see Fig. 1). There must be some unusual structures or lithologic variations beneath the Shihkang area to cause these strange rupture behaviors.

Both deep seismic reflection profiling and high-resolution shallow seismic reflection studies have been conducted to investigate the structures of the Chelungpu fault after the occurrence of the Chi-Chi earthquake. Two deep reflection seismic lines that crossed the Chelungpu fault, with targeting depth of $10 \mathrm{~km}$, were shot in the southern portion of the fault area (Fig. 1a) along the Choshuihsi river (passing through the epicenter) and the Wuhsi river, respectively. Each seismic line was $40 \mathrm{~km}$ long. In this paper, we present the results of this high-cost deep reflection survey. A very interesting, strong eastward-dipping reflection event on one of the seismic sections clearly indicates the relationship between the fault and the earthquake. Besides the deep seismic reflection surveys, we also conducted many shallow seismic reflection surveys on the hanging-wall side of the fault. The second part of this paper discusses the results of these widely distributed shallow seismic lines in the northern portion of the fault zone. This data also provides useful site information for determining where deep wells (2-5 $\mathrm{km}$ deep) could be drilled in this area in the future.

\section{GEOLOGIC SETTING}

The geology near the Chelungpu fault is relatively simple (CPC 1982 or Fig. 1). The structural layers involved are (from top to bottom): the Toukoshan formation (gravels, Pleistocene), the Cholan formation (sand and shale, late Pliocene), the Chinshui formation (shale, early Pliocene), and Miocene deposits composed mainly of sand and shale, the topmost being the Kueichulin formation (part of it being in the Pliocene age). The thrusting of the Chelungpu fault caused the Pliocene Chinshui and Cholan formations to move upward and become exposed on the eastern hanging-wall side, forming a hill. This thrust fault is estimated 
to have been shortened by a total of $13 \mathrm{~km}$ over the last two million years (Dr. Angelier, per. comm.). The western footwall side is covered with a $3 \mathrm{~km}$-thick Toukoshan gravel layer which formed the Taichung basin of relatively flat structural layers. Figure $1 \mathrm{~b}$ gives a gross outline of the underground structure of the area (Wang et al. 2000) compiled based on the oil-exploration type of seismic reflection studies and the concept of thin-skinned thrust model of Suppe (1980). It is obvious that the Chinshui shale is the key bed controlling the thrusting mechanism. This layer has a thickness of about $300 \mathrm{~m}$, being composed mainly of shales, and is probably overpore pressured (Suppe and Wittke 1977). The Chelungpu fault slides along this bed as a bedding fault, as can be seen by examining the seismic sections in this paper. The smoothly curved shape of the Chinshui shale is apparently the result of thrust faulting.

The Chelungpu fault is one of four west-verging thrust faults that developed along the deformation front of the western foothills of central Taiwan. Three other faults are also indicated in Fig. 1 (from west to east): the Changhua fault, the Shuangtung fault, and the Shuichangliu fault. Much research has shown that the most western Changhua fault might be a blind thrust, which has thrust above an older normal fault that related to the opening of the Taichung basin (Chang 1971; Chen 1978). The other two eastern faults cut through old rocks (Miocene or Oligocene) and have formed imbricated structures by large amounts of structural shortening over a distance range of at least $100 \mathrm{~km}$ (Suppe 1985). The rocks on the eastern side of the Shuichangliu fault are composed of Oligocene slate, as in the Hsuehshan mountain range, which have been low-grade metamorphosed.

\section{DEEP SEISMIC REFLECTION SURVEY}

The thin-skinned thrust model can nicely explain the effects of the 1999 Chi-Chi earthquake (Wang et al. 2000). Early in the sixties, perroleum geologists proposed this model as the main mechanism controlling the creation of the imbricated structures found in Taiwan's western foothills, based on the Chinese Petroleum Corporation's (CPC) seismic reflection and borehole drill data (Elishewitz 1963; Meng 1965). However, there are still questions regarding the range and the depth pertinent to the application of the model. The search for the basal decollement surface thus becomes an important issue. Deep seismic reflection surveys are needed to provide deep structural images, in order to evaluate the possible decollement structure.

Two deep reflection seismic surveys were carried out from November 2000 to March 2001 by the geophysical crew of the CPC, with the support of a government funding agency. The equipment and the survey parameters used for this deep reflection survey were listed in Table 1. The standard exploration-type of seismic data processing procedures for the CDP data were applied to reat this large data volume of deep seismic reflections. The procedures included crooked line correction, weathering-layer correction, deconvolution (36 ms predictive distance and $240 \mathrm{~ms}$ window length), filtering (10-50 Hz range), AGC (2 sec window length), velocity analysis (Constant Velocity Stack), residual statics ( $40 \mathrm{~ms}$ maximum), NMO stack, migration ( $70^{\circ}$ Finite-Difference), and depth conversion. The average layer velocities deduced from the CDP data analysis were $0 \mathrm{~km}(0 \mathrm{msec}): 2.0 \mathrm{~km} / \mathrm{s}, 2 \mathrm{~km}(1000 \mathrm{msec}): 3.9 \mathrm{~km} /$ s, $4 \mathrm{~km}(1600 \mathrm{msec}): 4.0 \mathrm{~km} / \mathrm{s}, 6 \mathrm{~km}$ (2200 msec): $5.2 \mathrm{~km} / \mathrm{s}, 8 \mathrm{~km}(2900 \mathrm{msec}): 5.6 \mathrm{~km} / \mathrm{s}, 10$ $\mathrm{km}(3300 \mathrm{msec}): 6.0 \mathrm{~km} / \mathrm{s}$. These velocity values are much higher than those normally found 
Table 1. Field Survey Equipment and Parameters for Deep Reflections.

\begin{tabular}{|c|c|c|c|}
\hline Items & Equipment & Items & Parameters \\
\hline Source & $\begin{array}{l}4 \text { or } 5 \text { Heavy } \\
\text { Vibrators } \\
\text { (HEMI50) }\end{array}$ & $\begin{array}{l}\text { Receiver interval } \\
\text { Source interval }\end{array}$ & $\begin{array}{l}40 \mathrm{~m} \\
80 \mathrm{~m}\end{array}$ \\
\hline Sweep length & $25 \mathrm{sec}$ & Near-offset & $160 \mathrm{~m}$ \\
\hline Sweep frequency & $8-54 \mathrm{~Hz}$ & Fold & 112 \\
\hline Stacking times & 16 & Sampling rate & $4 \mathrm{~ms}$ \\
\hline Recording time & $20 \mathrm{sec}$ & Record frequency & $8-128 \mathrm{~Hz}$ \\
\hline Channel number & 450 & Spread type & end-on \\
\hline Geophone array & 12 linear & & \\
\hline Recording system & $\mathrm{I} / \mathrm{O} \mathrm{II}$ & & \\
\hline
\end{tabular}

in the western plain area. Due to large offsets of the receiver spread, this velocity distribution is thought to be more accurate than those obtained from regular oil-exploration survey.

One of the seismic lines across the epicentral area (Chi-Chi) showed relatively good results. This line (HV2) followed the Choshuihsi river and was shot in a direction from east to west, as the region's structural layers dip to the east. Figure la shows the location of the line and Figure 2 shows the final sections. Figure 2a presents the depth section (after migration) without interpretation, while Figure $2 b$ shows the same section with the interpretation added on. Some stronger reflectors are drawn to indicate the possible basic structure variation in Fig. 2b. Because of gravel deposits on the surface along the river, the seismic signal is not good enough to reveal much detail. However, several reflection events are essentially visible. The most prominent one is a $40^{\circ}$ eastward dipping event that stands out in the middle of the section. This reflection event is no doubt related to the Chelungpu fault, or equivalently, the Chinshui shale layer. When approaching the surface, this dipping reflector bends a little, passes through a fault, called the Tachienshan fault under the Chi-Chi dam (Fig. 1a, \#5), and then follows a $30^{\circ}$ slope until breaking the surface. The Tachienshan fault (or the Hsiamao fault called by CPC) offsets the layers within the Cholan formation, which is also revealed in the CPC's geologic map (CPC 1982). The $30^{\circ}$ slope of the Chelungpu fault just below the surface is also confirmed by some shallow seismic reflection data (not show here). In the deep place, it is more interesting to see that this slant event turns at a depth of $8 \mathrm{~km}$ and becomes flat further to the east. The Chi-Chi earthquake source was located exactly at this deflection point (source depth of $8 \mathrm{~km}$, Chang et al. 2000). We believe that this dipping reflection event represents the flatand-ramp structure of the thin-skinned model. Different slopes along the fault surface affect the sliding movement in different ways. The deflection point at the ramp-and-flat geometry could be the place to accumulate plenty of stresses until setting off the earthquake.

On the footwall side of the Chelungpu fault (the western part of Fig. 2b), there are lowangle dipping events under the Pakuashan anticline and the Taichung basin, which may have 
Miocene rocks at depths of 6 to $10 \mathrm{~km}$ (revealed partly by the borehole data from CPC; Chang 1971). These Miocene layers seem to merge with the Chelungpu fault in the deep place on the eastern side. East of the Shuangtung fault, blurred seismic images suggest that flat or slightly westward dipping structures. This is quite possible since an anticline exists on the eastern mountain side of this seismic profile. This anticline could have crumpled up (decollement buckle; a thin-skinned phenomena) due to thrusting along the main fault. Compare to the Chinshui and the Cholan formations, the Oligocene rocks on the eastem side are much stronger, which may have transfered the tectonic forces to the western front where the Chi-Chi earthquake was initiated. The rock properties and structural geometry make the area east of the ChiChi epicenter more sustainable to outside pressure, thus forming the Sun-Moon-Lake (SML) earthquake gap as described in Wang et al. (2000).

Compared to the Choshuihsi line, the deep seismic reflection line along the Wuhsi river is of relatively poor quality. Figure 3 shows the resultant seismic section of the Wuhsi line. Its location is depicted in Fig. 1a. Two separate lines, HV3 and HV4, were shot independently to avoid the 'V-shape' curvature of the whole line. The final section puts these two parts together at their tie location as shown in Fig. 3. Figures $3 a$ and $3 b$ are the depth section with and without interpretation, respectively. Due to serious crooked-line geometry problems and highly oblique angles of the survey line direction with respect to the region's structural trend, the reflection signals in the eastern mountainous part of this section were largely lost. However, the image of the slant Chelungpu fault is still visible (Fig. 3b). To the west of this fault, the slightly dipping Pliocene and Pleistocene formations are nicely presented. They can be extended eastward even touching the Chelungpu fault. A $3 \mathrm{~km}$ depth for the Toukoshan formation is obvious, which can be controlled by the wells of the CPC (Chang 1971). We can draw different dipping reflection events on the hanging-wall side of the Chelungpu fault without much difficulty, although there may exist some ambiguities. The Shuangtung fault is conservatively determined with limited satisfaction. The dip angle of the Chelungpu fault was found to be about 20-30 degrees, which is much smaller than that on the Choshuihsi section. This dip angle decrease is expected, since the Chelungpu fault surface has been found to have a gentle tilting angle of 10 degrees toward the south (Wang 2002). Thus, the eastward dipping angles may become smaller toward the north. All the structural layers become flatter eastward, and may possibly merge together. The Wuhsi seismic section is compatible with the thin-skinned thrust mechanism.

Except for differences in the dip angles of the layers, the obtained Choshuihsi and Wuhsi seismic sections basically show similar structural pattern. On the hanging-wall side of the Chelungpu fault, the upward thrusting caused the Pliocene and Pleistocene formations to form a mono-syncline with a similar concave curvature. However, the Miocene layers between the Shuangtung and the Shuichangliu faults show significantly different dips on these two sections. It has been found that the lower Miocene rock outcrops along the Wuhsi line, i.e., the exposed rocks are older. By contrast, only the younger upper Miocence rocks are exposed along the Choshuihsi line. The difference in the dipping type of Miocene layers along these two lines may provide a possible explanation of the generation of the Puli basin. Higher thrusting movement along the Shuangtung fault in the Wuhsi river region may have dragged the hanging-wall structure a great amount, giving rise to higher tension in behind and opened the Puli basin. In 
(a)
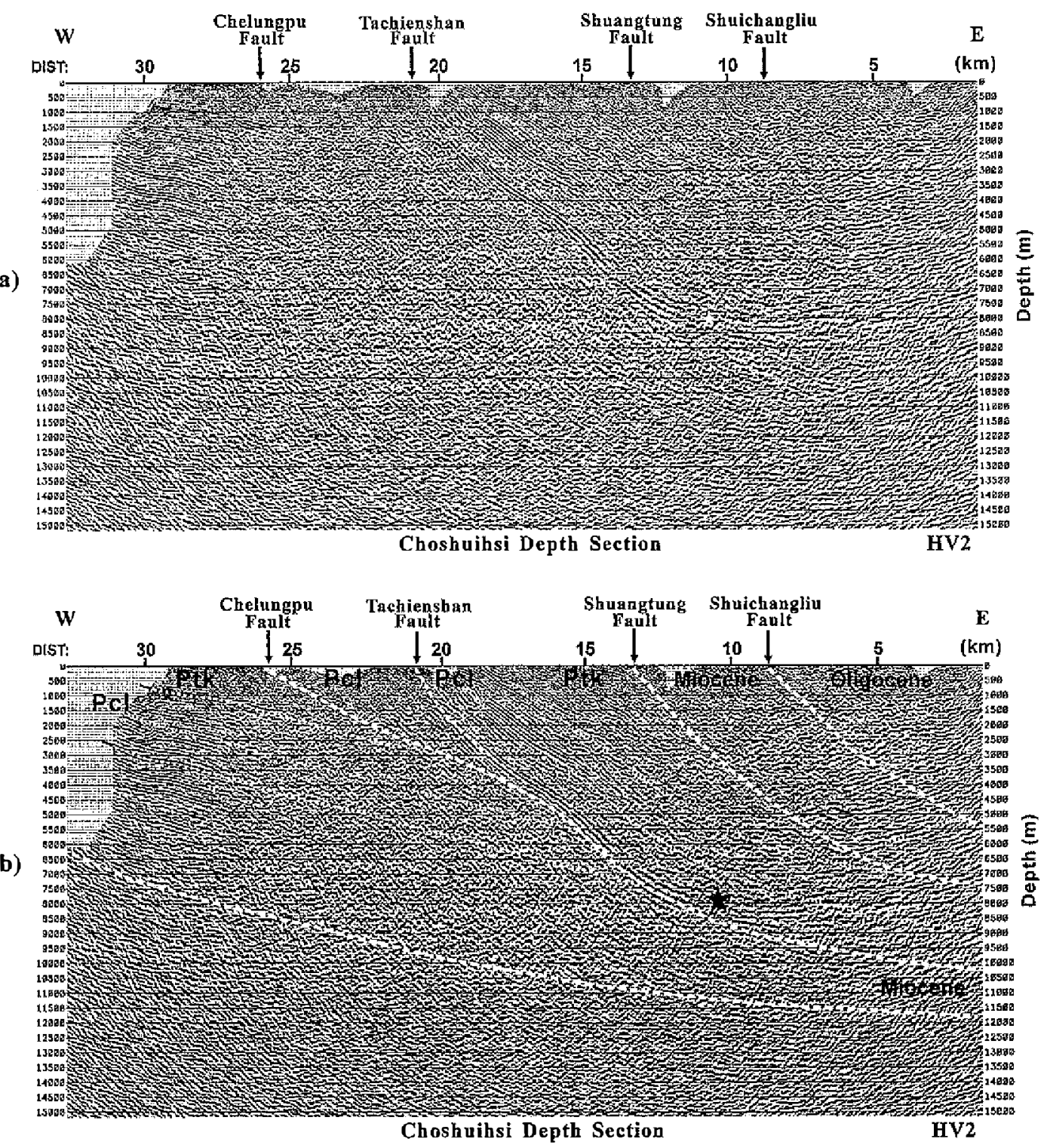

Fig. 2. The deep seismic reflection section along the Choshuihsi river. This line is named HV2 in Fig. 1a. (a) and (b) correspond to the final depth sections (after migration and depth conversion) without or with interpretation, respectively. The horizontal and vertical scales are kept at the same scale. The very clear dipping event across the section is unambiguously related to the Chelungpu fault surface which was activated during the 1999 ChiChi earthquake. The source location ( $8 \mathrm{~km}$ deep, denoted as a star) is deduced from the seismological observations (Chang et al. 2000). The source is located exactly at a place where the fault geometry changes from a ramp shape to a flat shape. 

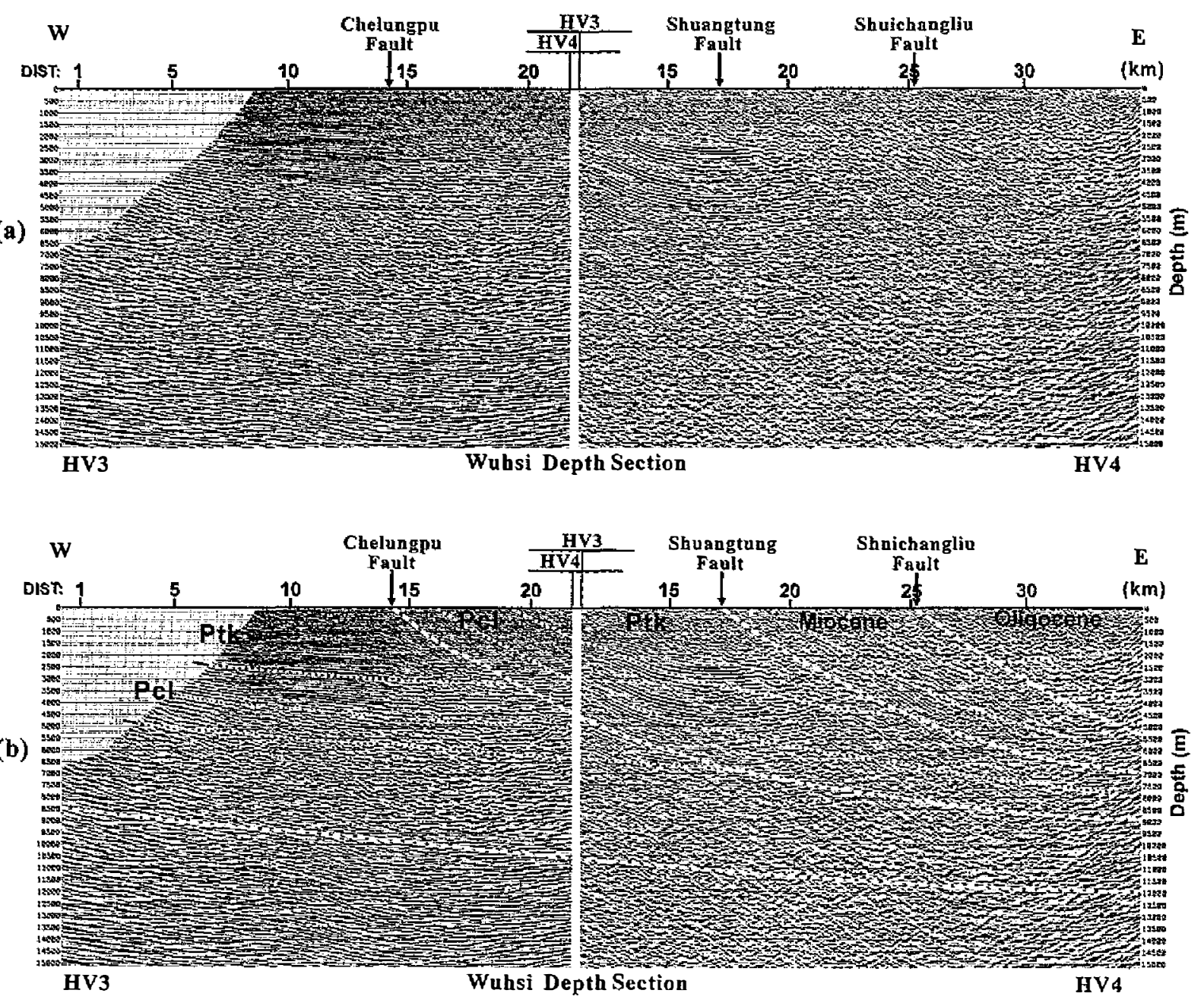

Fig. 3. The deep seismic reflection section along the Wuhsi river. (a) and (b) correspond to the depth sections without and with interpretation, respectively. 
the Choshuihsi region, because of the higher dip angle of the Chelungpu fault, decollement buckling on the hanging-wall side occurred, which may have reduced the interaction, so only sparse and small basins were created around the Sun-Moon-Lake. This difference in the compression situations deduced from the two seismic sections also shows that the Wufeng and Tsaotung area may suffer greater pressure, thus extruded more to the west (i.e., bending to the west; Fig. 1a).

Except for the upper structures, the deep decollement boundary is hardly seen on these sections. In the Choshuihsi line (Fig. 2b), there might have a blurred, dim signal around $10 \mathrm{~km}$ depth reluctantly representing a boundary. But it is under great uncertainty. In this paper, we still leave the problem of the decollement boundary unsolved.

\section{SHALLOW SEISMIC REFLECTION SURVEY}

Besides the costly deep reflection work, we also performed many shallow seismic reflection surveys to collect the data for investigating the near-surface structures in a more economi-

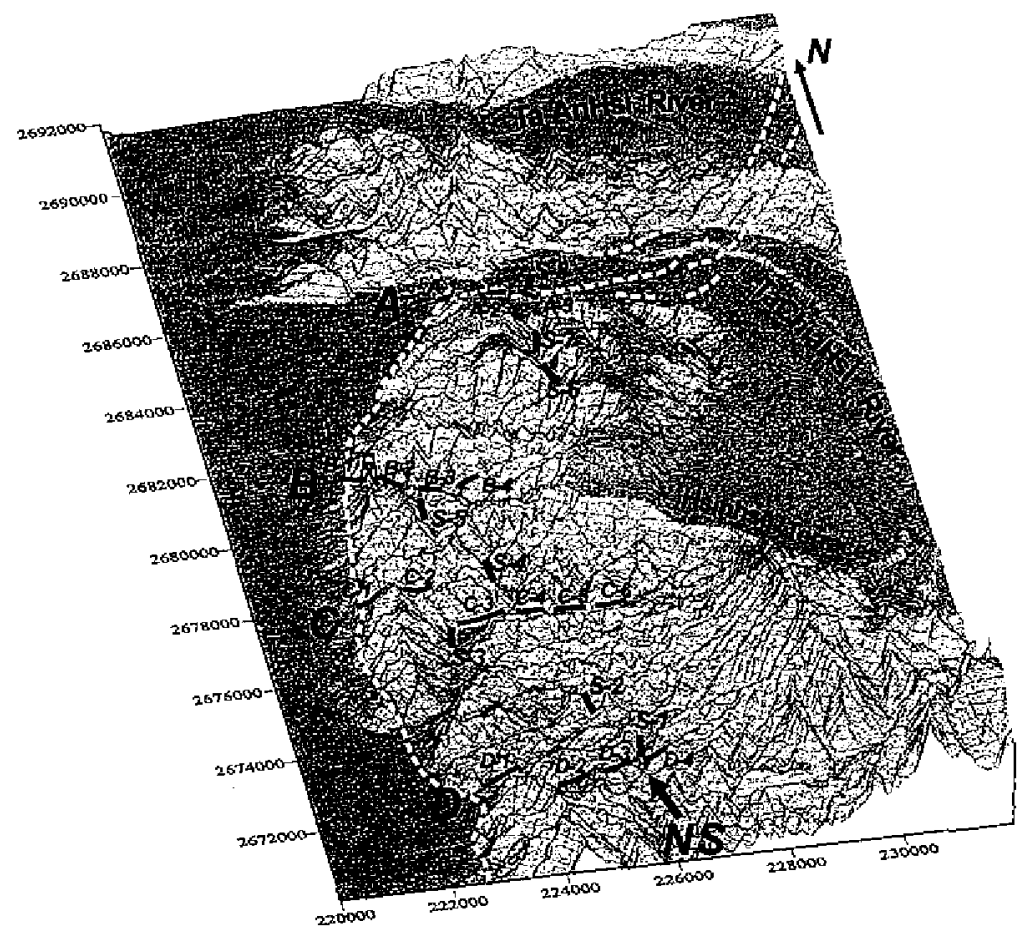

Fig. 4. The topography of the northern portion of the Chelungpu fault. There are several terraces in the eastern and northem sides of the area, which imply uplifted structures under them. The dashed line follows the surface ruptures of the Chelingpu fault. Locations of five seismic reflection profiles (A, B, C, D, and NS) are indicated. The location of the Fengyuan well is also denoted by a symbol of well tower. 
cal way. This work was concentrated in the northern portion of the Chelungpu fault (Fig. 4) where many abnormal behaviors occurred during the earthquake (Ma et al. 2001). Drilling of deep wells is under planning at this region (Ando et al. 2001). The 1999 Chi-Chi earthquake presents a rare opportunity to directly drill into the fault zone where large slip has recently occurred. After several shallow test wells drilled beside the fault (Tanaka et al. 2002; Wang et al. 2002), a deep drilling project has been intensively planned (Ando et al. 2001; Mori et al. 2002). This is an international project cataloged by the International Continental Drilling Project (ICDP). The shallow seismic survey serves as a part of this project to provide basic site information.

Over 20 shallow seismic reflection lines have been collected. Figure 4 indicates the location of these lines as well as the overall topography of the area. There are some high-level terraces, called the Hsinhse terrace group, developed on the eastern and the northern sides, which imply an uplift of the structures beneath them. This uplift has caused the migration of the Tachiahsi river toward the northeastern direction and left different levels of river terraces. A 'pop-up' structure has been proposed to describe the high-level terraces in the northern side, just south of the Shihkang region (Hsieh et al. 2001; Lee et al. 2002).

Although the shallow reflection seismics has a survey size limitation (at most $3000 \mathrm{~m}$ deep), it is much cheaper and easier to carry out in a rough topographic area as that shown in Fig. 4. A long, oil-exploration type of seismic line is always difficult, perhaps even impossible in this kind of region, with its rugged surfaces, winding roads and short accessible distances. The shallow seismic method has the merits of mobility, efficiency, high-resolution and costeffectiveness, which make it quite useful for mapping structures in a hilly area. The survey equipment and survey parameters of shallow seismic reflection were listed in Table 2. Most of the field work was carried out at night to avoid traffic noise. The data processing followed standard procedures for CDP data, except for the emphasis of some dip filters and static corrections (Wang 2002).

A total of twenty-five seismic lines were acquired (Fig. 4), which could be divided into 5 groups (profiles), as shown in Figs. 5 to 9. Each profile contains 3 to 8 sections, which are lined up to form a long profile. The horizontal and vertical scales of these profiles are kept

Table 2. Field Survey Equipment and Parameters for Shallow Seismics.

\begin{tabular}{cccccc}
\hline Items & Equipment & & Items & Parameters \\
\cline { 1 - 2 } \cline { 5 - 5 } Source & EWG-III impact pulse & & Receiver interval & $2 \mathrm{~m}$ \\
generator & & Source interval & $6 \mathrm{~m}$ \\
Receiver & OYO 40Hz geophone & & Near-offset & $100 \mathrm{~m}$ \\
Seismograph & DAS-1 96 channel & & Fold & 16 \\
& & & Sampling rate & $0.25 \mathrm{~ms}$ \\
& & & Low cut filter & $40 \mathrm{~Hz}$ \\
\hline
\end{tabular}




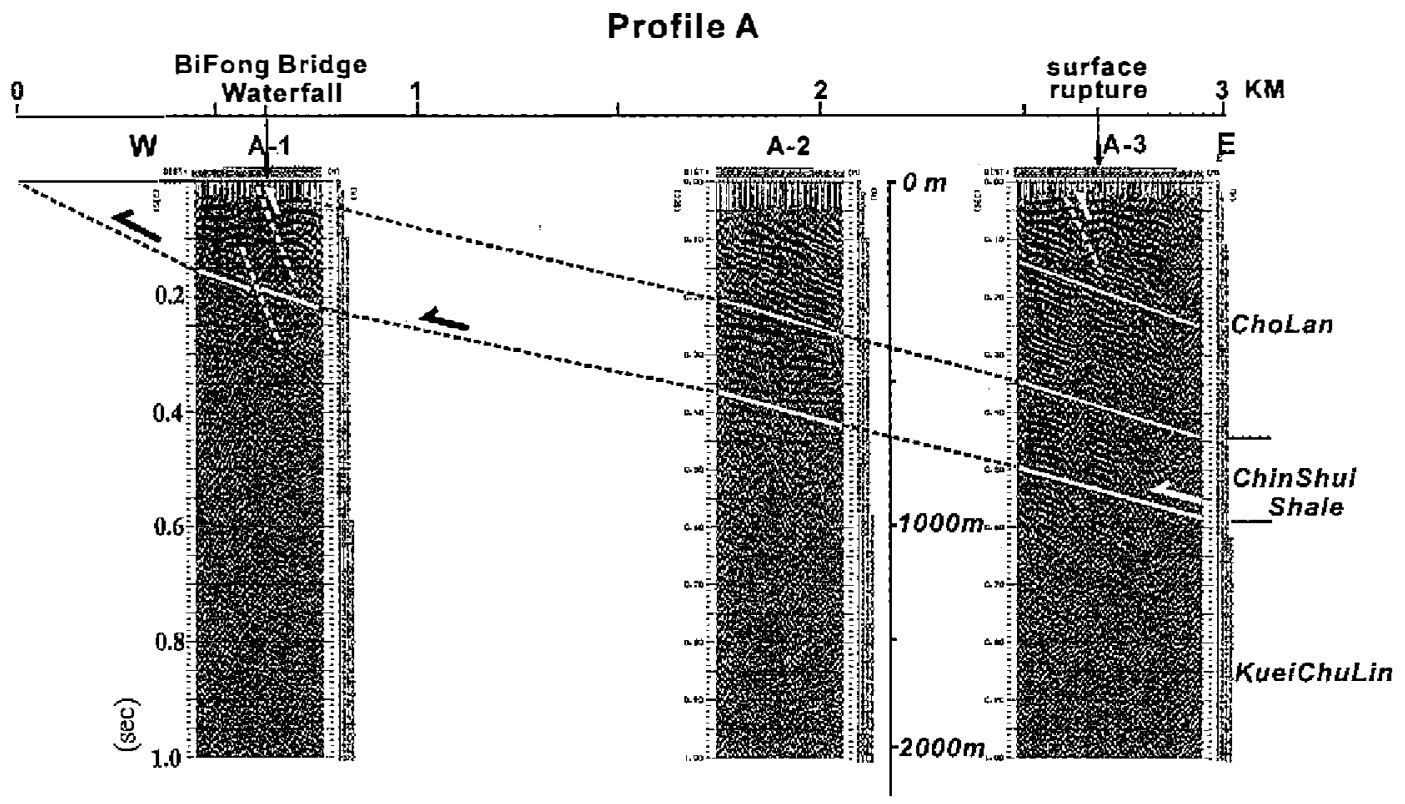

Fig. 5. Reflection seismic sections taken along Profile A, which is located on the southern bank of the Tachiahsi river. Large surface ruptures have occurred during the Chi-Chi earthquake in this area (Shihkang).

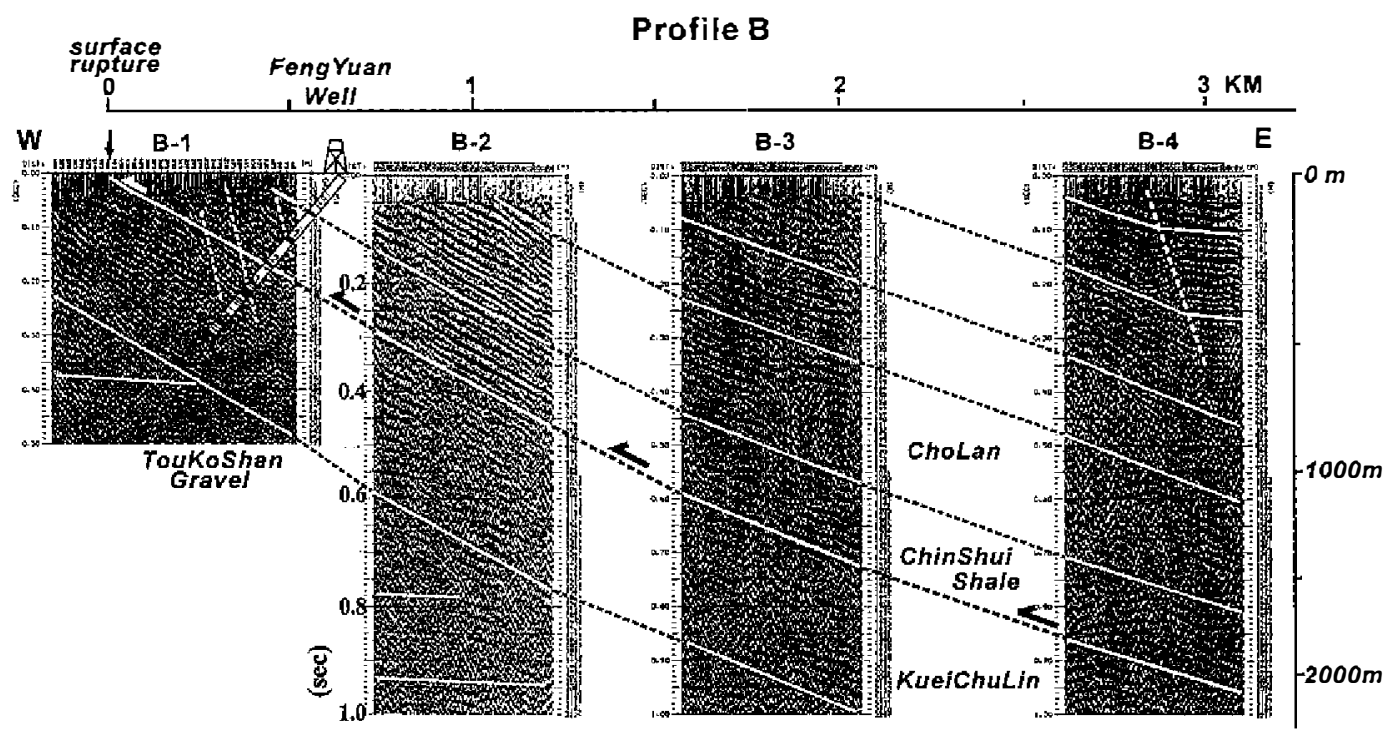

Fig. 6. Reflection seismic sections of Profile B along the Newlanhsi river. Section B-I is very close to the Fengyuan well (450m deep, Fig. 4) recently drilled (Tanaka et al. 2002; Wang et al. 2002). It is noticed that the event at the depth of $220 \mathrm{~m}$ of the well can be connected to the surface rupture place. 
approximately the same in order to show non-distorted structural images. The quality of the data is surprisingly good. The structures in the four E-W profiles (Profiles A to D) appear quite simple, full of eastward dipping layers with slightly varied dip angles between 18 to 35 degrees. By using the well-documented geologic map and the lithologic layers identified on the surface outcrops, we may assign different reflection layers on different parts of the sections. True amplitude seismic sections have also been prepared (not shown) to assist this layer identification. On Profile B (Fig. 6), we even have a recently drilled shallow well (the Fengyuan well, 450m deep, Tanaka et al. 2002) to control the layer. Some detailed structural variation due to faulting may be observed in these delicate, high-resolution seismic sections. For example, Profile B shows an apparent high-angle fracture on the upper part of its B-4 section, which may represent a minor fault that developed on the uplifted structure related to the generation of the highlevel Hsinhse terraces. This small fracture could be a part of the 'pop-up' structures of this area (Lee et al. 2002). Profile C (Fig. 7), which is a highly probable candidate site for a deep well drilling, shows that the target fault may be $0.5 \mathrm{~km}$ deep, $1 \mathrm{~km}$ distance from the surface fault trace, $1.2 \mathrm{~km}$ at $2 \mathrm{~km}$, and $2.5 \mathrm{~km}$ at $4 \mathrm{~km}$. These numbers may be used as reference for planning the deep drilling. We note that there is a Miocene-and-Pliocene Kueichulin formation under the Chelungpu fault (Chinshui shale), which has a thickness of about $800 \mathrm{~m}$ (Figs. 6, 7, and 8). An old fault (the Sani fault, Fig. 1a) is believed to be sited at the bottom of this layer and beneath it may be the younger Pleistocene Toukoshan gravel formation. Drilling to this deep-buried gravel layer is highly recommended to determine any significant relationships between the old and the new faults.

We also collected 8 short seismic lines (Profile NS) in the south-north direction parallel the Chelungpu fault or the structural trend direction (Fig. 9). The reflections observed in this $\mathrm{N}-\mathrm{S}$ profile presents very interesting up and down undulations. These dip variations and the ties between the E-W and N-S profiles allow us to construct a 3D fault surface, as shown in Fig. 9b. A very interesting swinging shape of the fault surface is found. The depressions on

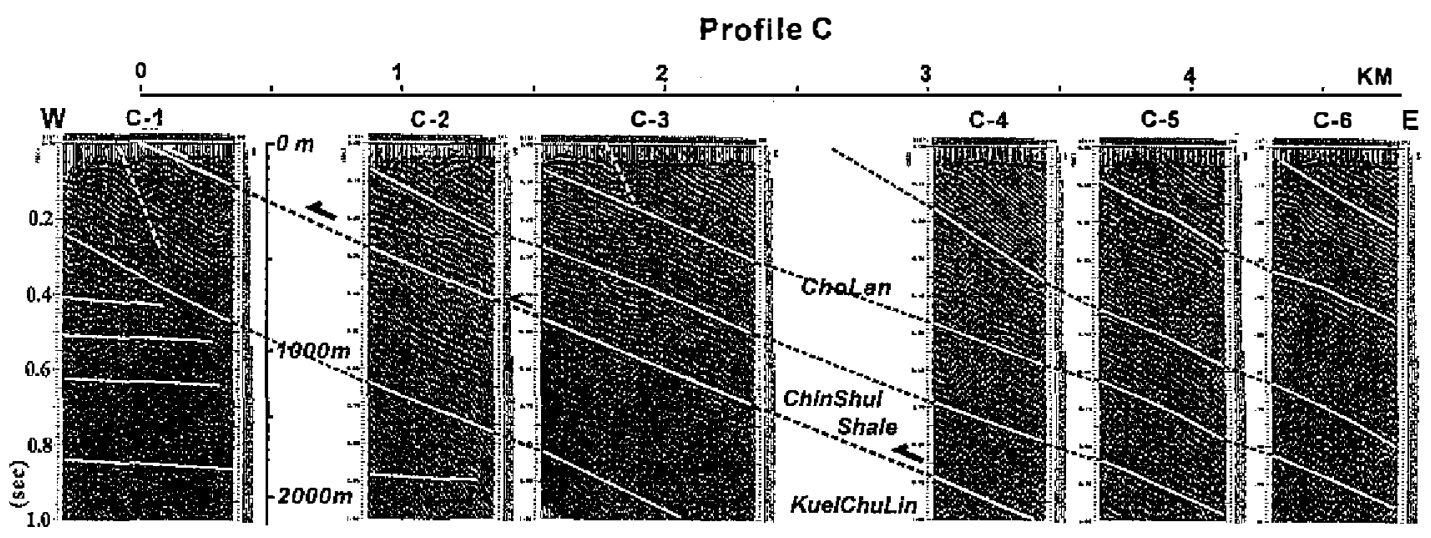

Fig. 7. Reflection seismic sections of Profile $\mathrm{C}$ along the Takunghsi river. Wide open spaces with low surface relief have made this area a possible location for deep well drilling. It is noticed that the Kueichulin formation, just under the Chinshui shale layer, has a thickness of about $800 \mathrm{~m}$. 


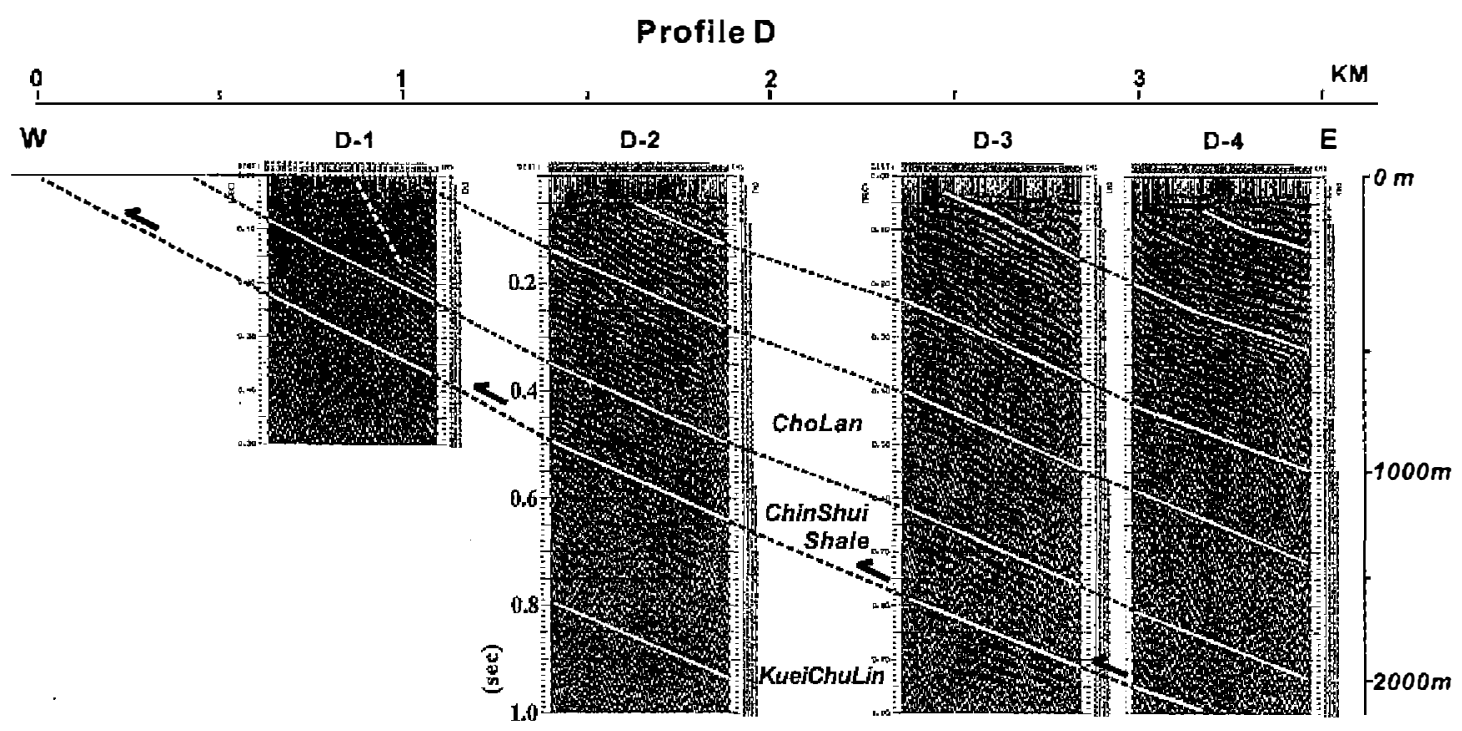

Fig. 8. Reflection seismic sections of Profile D along the Butzukunghsi river. All the layers dip evenly to the east.

this swinging surface are related to the westward flowing rivers in the area, which implies a close relationship of the geomorphology and the underground structure. Similar measurements have also been done for the southern portion of the fault (over 50 seismic lines, not show). Combining the deep reflection sections shown in Figs. $2 b$ and $3 b$ together with the shallow reflection results, we may obtain a more complete fault surface geometry for the whole Chelungpu fault (Fig. 10). This constructed 3D fault plane, besides dipping to the east, also shows a slight inclination to the south (about 10 degrees), which means that the fault surface becomes shallower as it moves from south to north, and is finally exposed at the surface along the banks of the Tachiahsi river in the Shihkang area. This structural variation can explain the abnormal rupturing orders found in the Fengyuan-Shihkang area. The fault surface may be very close to the surface here (as little as $200-400 \mathrm{~m}$ deep), so the ruptures rushed up and broke the surface during the earthquake.

The seismic sections presented in this study demonstrate a convenient way to map the structure of a wide hilly area. Further detailed mapping could be carried out if a target site (e. g., for drilling) is decided. Considering the cost and the effort of surveys, we should not ignore practical values of the shallow reflection seismics. The new generation of instrumentation may make the method even more powerful for geological field investigations.

\section{CONCLUSIONS}

From the above descriptions and discussions, we reach the following conclusions:

1) The results of deep reflection surveys reveal a $40^{\circ}$ dipping layer coincident with the Chelungpu fault surface. This layer bents at a depth of $8 \mathrm{~km}$ and becomes flat eastward. The Chi-Chi 


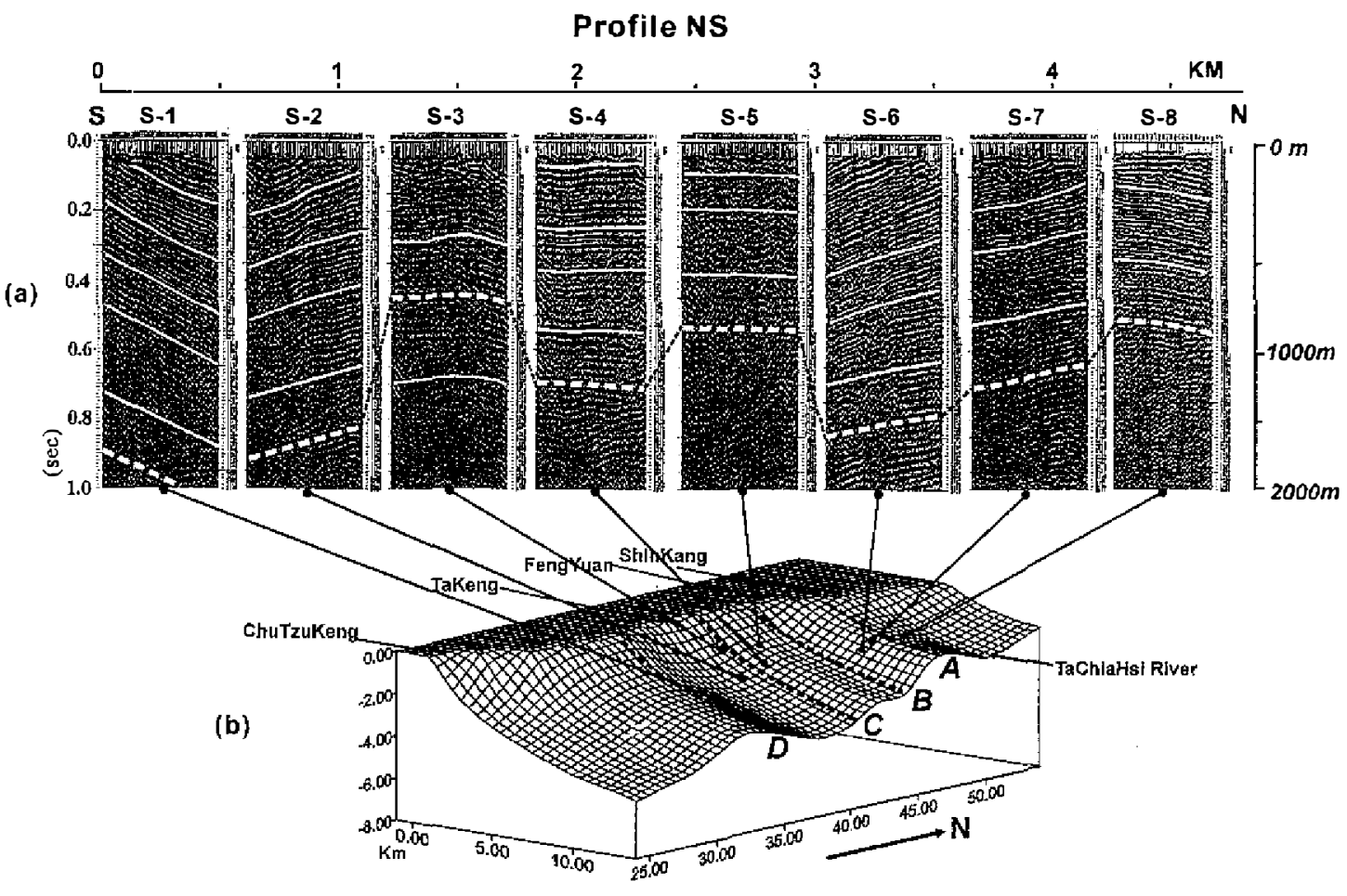

Fig. 9. (a) A series of seismic reflection sections along a north-south profile (Profile NS). The dip angle of each section varies in an up-and-down manner, which leads to the conceptualization of a 3D undulating structure for the Chelungpu fault surface (the northern portion), as shown in (b).

earthquake source was exactly located at the deflection point of this flat-and-ramp geometry.

2) The structures in the footwall side are slightly inclined to the east, with lesser dip angles than that of the hanging wall. The signal from the decollement is weak, however, it seems to merge with the flat part of the Chelungpu falt at its eastern side.

3) The structure of the hanging-wall side of the deep reflection section shows a decollementrelated buckling structure, which could be a result of the thin-skinned thrusting.

4) In the northern portion of the Chelungpu fault, the structures along four E-W trending shallow seismic profiles showed simple eastward dipping layers with slightly varied dip angles between 18 to 35 degrees.

5) The profile along Profile $C$, which is a candidate site of deep drilling, shows that the target fault (or Chinshui shale) may be $\theta .5 \mathrm{~km}$ deep at $1 \mathrm{~km}$ distance from the surface fault trace, $1.2 \mathrm{~km}$ at $2 \mathrm{~km}$, and $2.5 \mathrm{~km}$ at $4 \mathrm{~km}$. More than drilling to the Chelungpu fault surface, a further drilling of $800 \mathrm{~m}$ to reach the deep hidden Toukoshan gravel layer is recommended.

6) An up and down undulating fault surface was found along the south-north profile (Profile NS). The constructed 3D fault plane, however, shows a slight dip to the south with an angle 


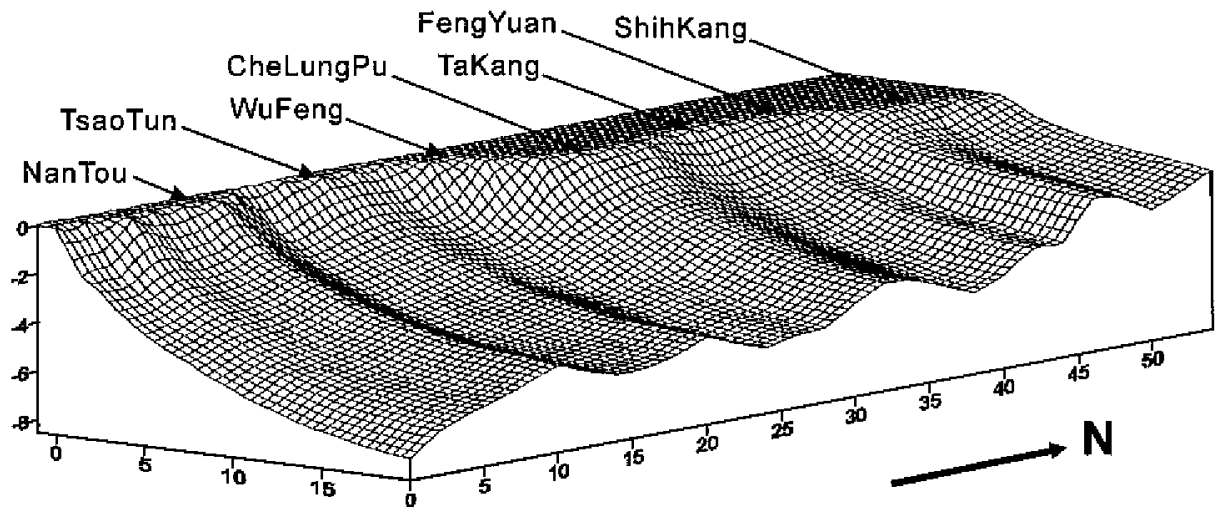

Fig. 10. Proposed swinging geometry of the Chelungpu fault surface. Note that the rise of the surface reaches its shallowest point near Fengyuan and Shihkang, where large surface ruptures occurred.

of about 10 degrees.

7) The inclined fault surface becomes shallower as it extends from south to north and is finally exposed at the banks of the Tachiahsi river. This leads to the abnormally large displacements in this area during the earthquake.

Acknowledgments We express our gratitude to the CPC geophysical crew, who have worked very hard to collect the valuable deep seismic reflection data. Many graduate and undergraduate students provided large amounts of labor for the shallow seismic field work, which is also highly appreciated. This research was supported by the National Science Council, Taiwan under grant NSC90-2119-M-008-005.

\section{REFERENCES}

Ando, M., Y. B. Tsai, M. Zoback, K. Suyehiro, H. Ito, J. Mori, and H. Tanaka, 2001: Drilling the seismogenic zone of the Chelungpu fault, Taiwan: Investigating physics of faulting for a recent large earthquake. ICDP Workshop on Drilling the Chelungpu Fault, Taipei.

Chang, C. H., Y. M. Wu, T. C. Shin and C. Y. Wang, 2000: Relocation of the 1999 Chi-Chi earthquake in Taiwan. TAO, 11, 581-590.

Chang, S. L., 1971: Subsurface geologic study of the Taichung basin, Taiwan. Petro. Geol. Taiwan, 8, 21-45.

Chen, J. S., 1978: A comparative study of the refraction and reflection seismic data obtained on the Changhua plain to the Peikang shelf, Taiwan. Petro. Geol. Taiwan, 15, 199-217.

Chen, Y. G., W. S. Chen, J. C. Lee, Y. H. Lee, C. T. Lee, H. C. Chang and C. H. Lo, 2001: Surface rupture of 1999 Chi-Chi earthquake yields insights on active tectonics of central Taiwan. Bull. Seism. Soc. Am., 91, 977-985.

Chinese Petroleum Corporation, 1982: The geological map of Miaoli, Taichung and Chiayi, 
Taiwan Petrol. Explor. Div. Publ., CPC, Taiwan, scale 1:100,000.

Elishewitz, B., 1963: A new interpretation of the structure of the Miaoli area in the light of the decollement tectonics of northern Taiwan. Petro. Geol. Taiwan, 2, 21-45.

Hsieh, M. L., Y. H. Lee, T. S. Shih, S. T. Lu, and W. U. Wu, 2001: Could we have predicted the northeastern turn of the 1999 Chi-Chi earthquake rupture using geological and morphologic data?. TAO, 12, 461-484.

Kao, H., and W. P. Chen, 2000: The Chi-Chi earthquake sequence: active, out-of-sequence thrust faulting in Taiwan. Science, 288, 2346-2349.

Lee, J. C., H. T. Chu, J. Angelier, Y. C. Chan, J. C. Hu, C. Y. Lu, and R. J. Rau, 2002: Geometry and structure of northern surface ruptures of the $1999 \mathrm{Mw}=7.6 \mathrm{Chi}-\mathrm{Chi}$ Taiwan earthquake: Influence from inherited fold belt structures. J. Struc. Geol., 24, 173192.

Ma, K. F., J. Mori, S. J. Lee, and S. B. Yu, 2001: Spatial and temporal distribution of slip for the 1999 Chi-Chi, Taiwan earthquake. Bull. Seism. Soc. Am., 91, 1069-1087.

Mori, J., H. Ito, and C. Y. Wang, 2002: Chelungpu fault drilling could resolve seismological issues. EOS, 83, 255.

Meng, C. Y., 1965: Lateral movement in the northem half of western Taiwan. Petro. Geol. Taiwan, 4, 89-92.

Shin, T. C., and T. L. Teng, 2001: An overview of the 1999 Chi-Chi, Taiwan, earthquake. Bull. Seis. Soc. Am., 91, 895-913.

Suppe, J., 1980: Imbricated structure of western foothill belt, south-central Taiwan, Petro. Geol. Taiwan, 17, 1-16.

Suppe, J., 1985: Principles of Structural geology, Prentice-Hall, Englewood Cliffs, 537pp.

Suppe, J., and J. H. Wittke, 1977: Abnormal fluid pressure in relation to stratigraphy and structure in the active fold-and-thrust belt of northwestern Taiwan. Petro. Geol. Taiwan, 14, 11-24.

Tanaka, H., C. Y. Wang, W. M. Chen, A. Sakaguchi, K. Ujiie, H. Ito, and M. Ando, 2002: Initial science report of shallow drilling penetrating into Chelungpu fault zone, Taiwan. $T A O, 13,227-251$.

Wang, C. Y., C. H. Chang, and H. Y. Yen, 2000: An interpretation of the 1999 Chi-Chi earthquake in Taiwan based on the thin-skinned thrust model. TAO, 11, 609-630.

Wang, C. Y., 2002: The detection of a recent earthquake fault by the shallow reflection seismic method. Geophys., 67, 1345-1352.

Wang, C. Y., H. Tanaka, J. Chow, C. C. Chen, and J. H. Hong, 2002: Shallow Reflection Seismics Aiding Geologic Drilling into the Chelungpu Fault of the 1999 Chi-Chi Earthquake, Taiwan. TAO, 13, 153-170.

Wu, F. T., R. J. Rau, and D. Salzberg, 1997: Taiwan orogeny: thin-skinned or lithospheric collision?. Tectonophys., 274, 191-220.

Yen, H. Y., Y. H. Yeh, and F. T. Wu, 1998: Two-dimensional crustal structures of Taiwan from gravity data. Tectonics, 17, 104-111. 